\title{
Systemically delivered insulin-like growth factor-I enhances mesenchymal stem cell-dependent fracture healing
}

\author{
TIMOTHY J. MYERS ${ }^{1, \star}$, YUN YAN ${ }^{1, \star}$, FROILAN GRANERO-MOLTO ${ }^{1}$, JARED A. WEIS $^{1}$, \\ LARA LONGOBARDI ${ }^{1}$, TIESHI LI ${ }^{1}$, YING LI ${ }^{1}$, CLARA CONTALDO ${ }^{1}$, HUSEYIN OZKHAN ${ }^{1}$, and \\ ANNA SPAGNOLI 1,2 \\ ${ }^{1}$ Department of Pediatrics, Division of Endocrinology, University of North Carolina at Chapel Hill, \\ Chapel Hill, NC, USA \\ ${ }^{2}$ Department of Biomedical Engineering, University of North Carolina at Chapel Hill, Chapel Hill, \\ NC, USA
}

\begin{abstract}
In this study, we examined the effectiveness of systemic subcutaneous delivery of recombinant Insulin-like growth factor (IGF)-I concurrently with primary cultured bone marrow-derived mesenchymal stem cell (MSC) transplant on fracture repair. We found that the fracture callus volume increased in mice with a stabilized tibia fracture that received IGF-I + MSC when compared with that in either untreated or MSC alone treated mice. In evaluating the callus tissue components, we found that the soft and new bone tissue volumes were significantly increased in IGF-I + MSC recipients. Histological and in-situ hybridization analyses confirmed a characteristic increase of newly forming bone in IGF-I + MSC recipients and that healing progressed mostly through endochondral ossification. The increase in soft and new bone tissue volumes correlated with increased force and toughness as determined by biomechanical testing. In conclusion, MSC transplant concurrent with systemic delivery of IGF-I improves fracture repair suggesting that IGF-I + MSC could be a novel therapeutic approach in patients who have inadequate fracture repair.
\end{abstract}

\section{Keywords \\ Insulin-like growth factor-I; mesenchymal stem cells; fracture healing; non-unions; endochondral ossification; regenerative medicine}

\section{Introduction}

Ten percent of all fractures occurring in the USA are complicated by impaired healing, resulting in non-unions, or delayed unions, causing severe disabilities (Einhorn 1995; Marsh 1998). What causes non-unions and delayed healing is not fully understood, but especially in atrophic non-unions (the most common form), it is assumed to be due to inadequacies of growth factors and/or stem cells. Lack of normal fracture repair often leads to surgical

\footnotetext{
(C) 2012 Informa UK, Ltd.
}

Correspondence: Anna Spagnoli, Department of Pediatrics, Division of Pediatric Endocrinology, 103 Mason Farm Road, 3341 MBRB, Campus Box: 7039, University of North Carolina at Chapel Hill, Chapel Hill, NC27599-7039, USA. Tel: 919-843-6904. Fax: 001-919-966-2423, spagnoa@med.unc.edu.

$\star$ These authors contributed equally to this work.

Declaration of interest: This work was supported by NIH NIDDK R01 5R01DK070929-06 to A. Spagnoli and by the Pediatric Endocrine Society (Lawson Wilkins Pediatric Endocrine Society) Research Fellow Award 2010-2011 to Y. Yan. All authors report no conflicts of interest. The authors alone are responsible for the content and writing of the paper. 
interventions, long periods of immobilization, pain, bone deformities, and sometimes death (Praemer et al. 1999). Current clinical approaches to enhance bone regeneration include autologous bone grafts, allo-grafts, bone-graft substitutes, and growth factors. Autologous bone graft remains the gold standard for treating non-unions, but drawbacks include limited supply and associated morbidities such as pain and infection (Kanakaris et al. 2007; Mahendra and Maclean 2007).

Fracture healing is a complex process in which several growth factors and specialized cell types from different bone niches respond to restore bone integrity and function (Gerstenfeld et al. 2003; Ai-Aql et al. 2008; Colnot 2009). There are many investigations aimed at enhancing fracture healing in non-unions, or delayed unions (Axelrad et al. 2007). Adult mesenchymal stem cells (MSCs), also known as multipotent mesenchymal stromal cells, have attracted special attention because of their potential role in tissue regeneration. Although promising, the use of MSCs in bone repair raises questions regarding their biology following transplantation.

Over the past decade, studies on MSCs have focused on their potential role in tissue regeneration. This function appears to be due to their ability to self-renew, their multilineage differentiation, and their ability to exert paracrine effects (Caplan 2007; da Silva Meirelles et al. 2008; Granero-Molto et al. 2008; Pittenger 2009). In other words, it has become evident that MSCs simultaneously function as multi-potent cells and as cells that provide the microenvironment for other progenitors, thus participating as both the "seed" and the "soil" for tissue regeneration. The contribution of different reservoirs of cells to fracture healing is not fully understood. MSCs are known to reside in a number of tissues such as periosteum, bone marrow (BM), synovium, trabecular bone, and fat, though the source of the MSCs can have a profound effect on the differentiation properties of the cells (De Bari et al. 2003; De Bari et al. 2006; Pittenger 2009). We previously reported a study on the dynamics of BMderived MSC homing and engraftment to fracture sites and their beneficial effects on bone strength when systemically transplanted (Granero-Molto et al. 2009). We were able to show that MSCs constitutively expressing Firefly Luciferase homed to the fracture site within three days post-transplant and were maintained for at least 14 days using bioluminescence tracing (Granero-Molto et al. 2009). Furthermore, using $\beta$-galactosi-dase-traceable MSCs we also saw that transplanted cells homed at the fracture site and specifically localized within the endosteal fracture line and along the endosteum (Granero-Molto et al. 2009). Interestingly, we saw that only about $3 \%$ of cells incorporated as bone cells into the newly forming cortical bone adjacent to the fracture line (Granero-Molto et al. 2011). These data suggested that the beneficial effects of transplanted MSCs were mostly due to regulation of endogenous targets through paracrine effects and led us to investigate growth factors which may play a role in this type of mechanism.

Insulin-like growth factors (IGF) have been reported to play a key role in bone formation and maintenance. The IGF family consists of two secreted growth factors, two receptors, and six high-affinity binding proteins. IGF-I and IGF-II are among the most abundant growth factors present in bone, and are likely to be important local regulators of fracture healing (Trippel 1998). IGF-I has also been reported to be involved in tissue regeneration, including skin, neural tissue, skeletal muscle, and fractured bones (Powell-Braxton et al. 1993; Clemens and Chernausek 2004; Nakasaki et al. 2008). Mice lacking IGF-R either totally, or in a tissue-specific manner, exhibit delayed embryonic skeletal growth and bone mineralization, retarded post-natal growth, low bone mineralization, and delayed facture healing (Liu et al. 1993; Wang et al. 2006; Cheng et al. 2011). In accordance, targeted overexpression of IGF-I in osteoblasts enhanced bone growth and mineralization (Zhao et al. 2000). IGF-I also has an important role in postnatal bone maintenance and postnatal bone mass. In inbred strains of mice, there is a correlation between levels of circulating IGF-I and 
bone mineral density (BMD; Rosen et al. 1997). In humans, circulating IGF-I and BMD correlate with incidence of fracture (Langlois et al. 1998). IGF-I administration resulting in acceleration of fracture healing in different animal models has been reported (Raschke et al. 2002; Schmidmaier et al. 2002; Fowlkes et al. 2006). In women with hip fractures, systemic administration of IGF-I along with IGFBP-3 improved healing, albeit modestly, and serum IGF-I levels were positively associated with a shorter time of healing (Boonen et al. 2002; Di Monaco et al. 2009).

We recently reported that the transplant of MSCs retrovirally transduced to express IGF-I further improved fracture healing, promoting new bone formation compared to MSCs alone (Granero-Molto et al. 2011). Clinical studies intended to deliver factors using viral vectors have been associated with tragic fatalities likely due to the incontrollable toxicity and immune responses as well as lack of specific targeting for genomic incorporation that has led to cancer development (Hacein-Bey-Abina et al. 2010). Although work is ongoing to alter viral vectors to make them safe, this clinical approach is currently impracticable and based on these fatalities the U.S. Food and Drug Administration (FDA) banned gene therapy trials using retroviral vectors in blood stem cells in April of 2003. Subcutaneous administration of IGF-I has been recently approved by the FDA to treat IGF-I deficiency. Safety data and post-marketing analyses have not shown serious side effects associated with IGF-I therapy, with a hypoglycemic response seen in both healthy and IGF-I-deficient patients (Guler et al. 1987; Kerr et al. 1993). The overall goal of this study is to determine the effectiveness of the combination of IGF-I with MSC in fracture repair in a setting that would be closer to its clinical application. For this purpose, we examined the effects of systemic subcutaneous delivery of recombinant IGF-I via mini-osmotic pumps concurrent with MSC transplant in four groups of mice with tibia fracture: untreated control, MSC only, IGF-I only, and IGF-I plus MSC (IGF-I + MSC). We found that IGF-I + MSC significantly improved fracture repair in vivo, significantly increased the fracture callus soft tissue compared to either control untreated mice or MSC alone and IGF-I alone treated mice. New bone content in IGF-I + MSC mice was also increased compared to that in control mice. Furthermore, we found that callus volumes correlated with the callus force and toughness indicating a beneficial functional effect to the healing process.

\section{Materials and methods}

\section{Reagents and materials}

Recombinant biotin conjugated anti-mouse CD34, CD45 and CD11b were from eBiosciences (San Diego, CA). Recombinant human IGF-I was purchased from Gropep Bioreagents (Adelaide, Australia).

\section{Animal studies}

All animal procedures were approved by the Institutional Animal Care and Use Committee at the University of North Carolina-Chapel Hill. A total of 40 mice were used for this study with three mice removed due to unstandardized fractures (two Control and one Control + MSC) leaving the following groupings: Control $(n=7)$, Control + MSC $(n=5)$, IGF-I $(n=$ $9)$ and IGF-I + MSC $(n=6)$, Control + MEF $(n=5)$, and IGF-I + MEF $(n=5)$. All mice were scanned by micro-computed tomography $(\mu-\mathrm{CT})$ and following imaging two mice per group were used for histological analysis with one Control + MSC sample lost during paraffin processing; four mice per group were subjected to biomechanical testing (BMT) of which one Control + MSC was excluded due to an instrument error. 


\section{Systemic delivery of IGF-I and stabilized fracture animal model}

One day prior to fracture, 8-12-week old female FVB-NJ syngenic mice (Jackson Laboratories, Bar Harbor, MA) were anesthetized using 2.5\% isoflurane to allow a miniosmotic pump, model 1002 (Alzet Osmotic Pumps, Cupertino, CA), designed to deliver a standard, continuous dose of Phosphate buffered saline (PBS) alone, or recombinant human IGF-I $(50 \mu \mathrm{g} / \mathrm{kg} /$ day $)$ in PBS over 15 days, to be surgically implanted subcutaneously on the back of each mouse as recommended by the manufacturer. The pump was implanted 1 day prior to fracture to minimize the stress to the animal by performing the two procedures (pump implant and fracture) in 2 days and to allow increased levels of IGF-I at the inception of the fracture repair process. The incision was then closed with 5-0 silk sutures (Ethicon, Somerville, NJ) using a simple interrupted pattern. As previously reported, stabilized tibial fractures were produced in anesthetized mice using $2.5 \%$ isoflurane by intramedullar fixation with a $0.3 \mathrm{~mm}$ stainless steel pin (Fine Science Tools, Foster City, CA) inserted through the patellar tendon inside the medullar canal of the tibia followed by a closed fracture performed using a three-point bending device with a standardized force that produced a single standard transverse fracture (Granero-Molto et al. 2009). Every fractured sample was thoroughly assessed in all three planes following $\mu$-CT scanning for fracture quality; fractures with multiple fragments or displacement were excluded. For pain control, buprenorphine $\mathrm{HCl}(0.5 \mathrm{mg} / \mathrm{kg})$ was administered subcutaneously, administration was repeated as needed.

\section{Isolation and expansion of primary MSCs or mouse embryonic fibroblasts}

Primary cultures of BM-derived MSCs were obtained by flushing the BM from the long bones of 4-6-week old syngenic mice as previously reported (Spagnoli et al. 2005). BMnucleated cells were cultured for 7-10 days without passaging, and plastic-adherent primary $\mathrm{BM}$ cells were isolated from contaminating hematopoietic cells through immunodepletion of CD45, CD11b, and CD34 positive cells using the MACS system (Miltenyi Biotech, Auburn, CA). As previously reported, this purification yields cells that are greater than $85 \%$ positive for the common MSC markers CD44, CD73, and CD29 (Granero-Molto et al. 2009). Mouse embryonic fibroblasts (MEFs) from C57Bl/6 mice were obtained from American Type Culture Collection (Manassas, VA) and expanded in culture as indicated by the supplier with transplanted cells being less than passage 5 . After fracture, mice were transplanted systemically with $1 \times 10^{6}$ MSCs or MEFs in $200 \mu \mathrm{L}$ sterile normal saline $(0.9 \%$ sodium chloride) by tail vein injection, or not injected at all. While establishing our transplant model, we injected well over 10 mice with saline-alone and did not find any evidence of either systemic or local healing effect (data not shown).

\section{Micro-computed tomography ( $\mu-\mathrm{CT}$ ) analysis of fracture calluses}

Fractured tibias were dissected 14 days post-fracture and following removal of the pin, scanned by $\mu$-CT (Scanco Medical $\mu$-CT 40). $\mu$-CT images were obtained at $55 \mathrm{kVp}, 145$ $\mu \mathrm{A}, 300 \mathrm{~ms}$ integration time using $12 \mu \mathrm{m}$ voxel resolution along a $6.3 \mathrm{~mm}$ length of the tibia centered at the fracture line with a total scanning time of approximately $1 \mathrm{~h}$ (Reynolds et al. 2007). Three-dimensional reconstructions were done using Analyze 9 software (AnalyzeDirect, Overland Parks, KS). Tissue composition was measured by quantifying the positive voxels within each threshold range for soft tissue, new bone, cortical bone, and highly mineralized bone separately based on a parametric thresholding study combining serial $\mu$-CT scanning and histological analysis described previously (Granero-Molto et al. 2009; Weis et al. 2010). Representative $\mu$-CT reconstructions of coronal sections (360 $\mu \mathrm{m}$ in width) surrounding the center of the fracture callus (dashed lines) of either soft tissue or new bone without cortical bone are provided. These pictures are representative cubed sections in the middle of the fracture callus and therefore contain tissue around and through 
the cortical bone making the diameter appear smaller than reality; however, the blacked out sections do provide the approximate location and area of the cortical bone.

\section{Biomechanical testing (BMT)}

Following $\mu$-CT analysis, 14-day post fracture samples were subjected to distraction-tofailure BMT. As previously reported, the bone ends were embedded with polymethylmethacrylate and loaded into the Electroforce system ELF 3200 (Bose Corp., Eden Prairie, MN; Granero-Molto et al. 2009). The displacement rate was set at $0.25 \mathrm{~mm} /$ min and a force-displacement curve recorded to calculate the ultimate displacement (maximum distance at failure), ultimate force (maximum force at failure), toughness (area under the curve), and modulus of elasticity (maximum slope) using the WinTest Control Software.

\section{Histology and in-situ hybridization}

Tibias were dissected at 14 days post-fracture, fixed in $4 \%$ paraformaldehyde for $24 \mathrm{~h}$, scanned by $\mu$-CT, then decalcified in $10 \%$ EDTA solution for 2 weeks, embedded in paraffin, and the entire callus was sectioned at $6 \mu \mathrm{m}$ (Granero-Molto et al. 2009). We have chosen a transversal plane for our histological sections to more accurately assess the heterogeneity of the healing tissue. As described by Gerstenfeld et al. (2005), the longitudinal plane lacks accuracy in both the cross-sectional area and tissue heterogeneity, which can be overcome by assessing the transversal plane with multiple sections within the callus. To determine the ideal sections for analysis, the center of the fracture gap was identified after sectioning the entire callus as the largest diameter of the callus size in which the fracture line was clearly demarked following hematoxylin and eosin (H\&E) staining; all further histological analyses were performed within $500 \mu \mathrm{m}$ of the center of the fracture line. A minimum of six sections were analyzed every $250 \mu \mathrm{m}$ for each procedure. H\&E and Safranin O/Fast Green staining were performed at the animal histopathology core at UNC as previously reported (Granero-Molto et al. 2009, 2011). In-situ hybridization (ISH) analysis was performed as previously described (Deal et al. 2006). Plasmids with cDNA insertions of mouse Collagen (I)-a-1 chain (Coll) and Osterix (OSX) probes were provided by G. Karsenty (Columbia University), while the probe for mouse Collagen (X)-a-1 chain (Col10) was provided by D.G. Mortlock (Vanderbilt University). Images were taken using an Olympus BX51 microscope with a DP71 camera. Quantification of the in-situ hybridization imaging was performed through the use of custom-designed image analysis code for MATLAB (Mathworks, Natick, MA), whereby a line was drawn around each tissue section of the callus to identify a region of interest (ROI) as previously reported (Granero-Molto et al. 2011). Within the ROI, total area, positive area, and the summed intensity were measured.

\section{Statistical analysis}

Data are presented as mean \pm standard error mean. Data had a normal distribution as tested by the Kolmogorov-Smirnov normality test. Statistical analyses were performed using oneway ANOVA followed by Bonferroni's Multiple Comparison post-hoc test, or linear regression analysis using GraphPad Prism 5 software (GraphPad, San Diego, CA). Statistical significance is set at $p<0.05$. 


\section{Results}

\section{MSC transplant combined with systemic delivery of IGF-I induces changes in the material properties of fractured calluses}

To investigate the effects of systemic IGF-I and MSCs on fracture repair, a murinestabilized tibial fracture model was employed in mice receiving subcutaneous mini-osmotic pumps designed to deliver a standard and continuous dose of either PBS alone, or recombinant human IGF-I. Immediately following fracture, a segment of either the PBS or IGF-I implanted mice received an intravenous transplant of $1 \times 10^{6}$ primary cultured and purified MSCs isolated from syngenic donor mice (IGF-I + MSC or MSC alone), while the other mice were left untransplanted (IGF-I alone or control). Three-dimensional reconstruction of the $\mu$-CT results of 14-day fracture calluses enabled us to quantify the total callus volume. Callus specimens from IGF-I-treated mice had increased volume compared with those from the control mice that were left untreated, and calluses from the IGF-I + MSC recipients were almost twofold larger than calluses from control mice (Figure 1A). Despite an upward trend, no significant differences were noted among the three treatments (Figure 1A). H\&E staining of transversal sections from the center of the fracture gap confirmed the volume increase in IGF-I + MSC recipients and also displayed signs of cartilage and new bone formation in those samples (Figure 1B). These results demonstrate that systemically delivered IGF-I can combine with transplanted MSCs at the site of injury to stimulate increased callus tissue formation.

We next aimed to determine the composition of the tissue responsible for the increased callus volume. The $\mu$-CT callus renderings were analyzed for new bone volume and soft tissue content measured according to our previously reported thresholding study (GraneroMolto et al. 2009). Figure 2A shows that soft tissue increased almost 1.5 -fold over control in the presence of systemically delivered IGF-I (Figure 2A). The addition of transplanted MSCs to IGF-I in IGF-I + MSC recipients further increased the soft tissue content over all other samples, almost 2.5-fold over control, twofold over MSC alone and 1.5-fold over IGFI alone. As seen in representative 3-D renderings, the increased soft tissue appeared to be responsible for the majority of the volume increase for both IGF-I and IGF-I + MSC calluses and was most strongly observed within the center of the callus, immediately flanking the fracture gap (Figure 2B). These results indicate a role for both IGF-I and MSC contributing to the increase in soft tissue volume.

Along with the soft tissue, new bone also increased in IGF-I and IGF-I + MSC transplant calluses compared to that in controls (Figure 2C). Calluses from IGF-I and IGF-I + MSCtreated mice exhibited an increase of new bone especially along both the periosteal and endosteal surfaces (Figure 2D). Unique to IGF-I + MSC-treated calluses though, the increased new bone could be found throughout the callus and already forming and strengthening the outer edges of the callus (Figure 2D, arrows), indicating the onset of the osteogenic phase and transition from a soft to bony callus. An upward trend, though not significant, was seen among the three treatment groups. These results therefore suggest that the increase of bone is due to IGF-I-dependent osteogenic differentiation, while the MSCs are providing a greater amount of regenerating tissue for the growth factor to influence.

To determine the specificity of the effects of the MSCs, we also transplanted MEFs in fractured mice with control- or IGF-I-containing osmotic pumps. Transplanted MEFs had no effect on the healing callus either with PBS or with IGF-I (Supplementary Figure 1). There was no statistical difference between the IGF-I alone and IGF-I + MEF samples in the total volume (Supplementary Figure 1D), new bone (Supplementary Figure 1E), or soft tissue (Supplementary Figure 1F). IGF-I + MEF did have significantly less soft tissue than IGF-I + MSC similar to IGF-I alone (Supplementary Figure 1F). Likewise, in control samples 
transplanted with MEFs, there was no difference in either total volume (Supplementary Figure 1A), new bone (Supplementary Figure 1B), or soft tissue (Supplementary Figure 1C) compared to control or MSCs alone. These results strongly suggest the specific effects of transplanted MSCs when combined with IGF-I treatment.

In previous studies we found that MSCs alone had significant effects, although in those studies MSC recipients did not undergo mini-osmotic pump implant (Granero-Molto et al. 2009). Although we found a trend toward an increase of callus volumes in MSC recipients, this was not significant. Therefore, we tested whether the implant by itself had some effects on the MSC's fracture regenerative abilities. As shown in Supplemental Figure 2, we found that MSC recipients that did not undergo pump implantation showed increased callus volumes and these MSC-dependent effects were blunted in mice that underwent pump implantation (Supplementary Figure 2). We speculate that the wound-healing repair process of the implanted region may have reduced the MSC-dependent effects on fracture healing as BM-MSCs have been reported to home and improve epithelial/dermal wound healing (Sasaki et al. 2008).

\section{IGF-I + MSC transplant increases the callus endochondral ossification process}

Formation of new bone occurs by two main processes: endochondral ossification which is the replacement of a mineralized cartilage support with bone and intramembranous ossification where osteoblasts directly produce bone. Due to the increase in soft tissue and new bone, we further analyzed the localization of the new bone within the callus through histological studies. Safranin O staining reveals that in MSC and IGF-I alone recipients, the callus cartilaginous tissue was mainly localized in the outlying regions of the callus (Figure 3A). In IGF-I + MSC recipients, we found that the cartilaginous template was pervasive throughout the callus and it was a major tissue component at the fracture line (Figure 3A). Also interesting to note was the interlacing of Fast Green (bone tissue) staining within the Safranin O stained areas in IGF-I + MSC samples, suggesting an increased endochondral ossification process (Figure 3A). In-situ hybridization of adjacent sections corroborated the Safranin O/Fast Green findings with the cartilage marker Col1O primarily highlighting the regions where the Safranin O stained the cartilage (Figure 3B). Quantification of the Col10 positive area in each sample revealed an increase in Col10 expression in IGF-I-alone samples over control and over IGF-I + MSC recipients, indicating that IGF-I + MSC accelerated the endochondral ossification process (Supplementary Figure 3A). To further support such acceleration, we found that the early osteoblast marker Osterix, which corresponded with the regions where the Fast Green highlighted the newly forming bone (Figure 3B), was increased in IGF-I + MSC samples over IGF-I-alone and control (Supplementary Figure 3B). We also noted that Osterix was increased in all treated samples over controls (Supplementary Figure 3B). These findings suggest that all treated samples utilize the intramembranous ossification process (through osterix-positive osteoblast progenitors), especially MSC transplanted samples and, combined with the Col1O results, that in IGF-treated samples endochon-dral ossification was favored, but only in IGF-I + MSC samples had the ossification processes progressed to the point of newly formed bone. This was further confirmed by measuring the expression of the bone marker, Collal, which had significantly increased expression only in IGF-I + MSC recipients, especially in areas where the cartilaginous template was already replaced by bone indicating a more advanced stage of cartilage mineralization and bone formation (Figure 3B and Supplementary Figure 3B). Taken together, histological and in-situ hybridization analyses indicate that IGF-I + MSC induces an acceleration of callus new bone formation mostly progressing through endochondral ossification. 


\section{IGF-I + MSC improves callus biomechanical properties}

Lastly, we tested for a functional improvement on fracture healing. To investigate this, the dissected tibias from each of the four groups were subjected to distraction-to-failure BMT. The means for the ultimate force (Figure 4A), the energy (toughness; Figure 4D), the ultimate displacement (data not shown), and the stiffness (data not shown) required to rebreak the fractured healing bones were not significantly different, though there was a trend to increased force $(p<0.054)$ and toughness $(p<0.056)$ with IGF-I + MSC transplanted samples. When we performed a linear regression analysis to determine how the soft tissue and new bone the force and energy had a significant positive relationship with the soft tissue and new bone (Figure 4B-C, E-F) as well as the total volume (data not shown; $p<0.05 ; r^{2}$ $=0.27$ to force; $p<0.025 ; r^{2}=0.33$ to toughness), with the samples from IGF-I + MSC recipients showing the highest values for force, toughness, and tissue volume components. Taken together these results indicate that during repair, increased callus volumes determined both by the soft and new bone tissues contribute to an improvement of the biomechanical functionality of fractures with the IGF-I + MSC displaying larger volumes associated with higher biomechanical properties. Thus, this clear relationship between size and the improvement in mechanical properties indicates that IGF-I + MSC enhanced the strength and elasticity of the callus through the stabilization and accelerated formation of repairing tissues.

\section{Discussion}

In this study, we demonstrated that in fracture repair the systemic delivery of IGF-I concurrent with MSC transplant increases total, soft, and new bone callus volumes. Increased callus volumes correlated with improved quality of healing and corresponded to an acceleration of new bone formation most likely through endochondral ossification. This was done by using quantitative $\mu$-CT analysis in combination with BMT and supported by classical histological analysis. Our results provide critical information for the clinical implementation of MSC combined with IGF-I in patients with inadequate fracture repair, such as non-unions.

In recent years, there has been an escalating interest in developing new therapies using cells that can promote repair of nonhematopoietic tissues (Prockop 1997; Caplan 2007; Prockop and Olson 2007; Pittenger 2009; Prockop 2009). Among the cells being tested are the adult stem/progenitor cells from BM often referred as MSCs, but more recently also as multipotent mesenchymal stromal cells (Dominici et al. 2006). For many years MSCs were thought to have a predominantly supportive role in repair. However, the paradigm concerning MSCs has shifted dramatically as MSCs possess several properties that make them an attractive candidate in regenerative therapies: (1) they can differentiate into distinctive end-stage mesenchymal cell types; (2) they can secrete bioactive molecules that regulate the regenerative microenvironment of an injured tissue and therefore influence surrounding cells (Prockop 1997; Caplan 2007; da Silva Meirelles et al. 2008; Pittenger 2009); (3) they reside in multiple tissues and are considered part of the innate healing process (Bielby et al. 2007); (4) they have immunomodulatory effects (Nauta and Fibbe 2007; Uccelli et al. 2008); (5) they can be isolated, expanded in culture, and returned in autologous transplants. These properties are consistent with the multipotentiality of MSCs and provide evidence of the ample regenerative capacities of these cells.

MSCs have been tested in animal fracture models as well as in limited clinical studies in patients with non-unions (Hernigou et al. 2005; da Silva Meirelles et al. 2008). Although well-controlled clinical trials need to be initiated, the vast majority of the animal studies reported that MSCs have beneficial effects on bone regeneration (Granero-Molto et al. 2008). We have previously reported that MSC transplant into a stabilized murine tibial 
fracture model improved fracture healing through better organization of the callus, leading to a decrease in the brittleness and structural rigidity of the callus (Granero-Molto et al. 2009). Here, we show the beneficial effects of MSC treatment in combination with IGF-I treatment. By comparing transplanted MSC-IGF-I to transplanted MEF-IGF-I, we also demonstrate the uniqueness and specificity of the effects of transplanting MSC-IGF-I as there were no beneficial increases in MEFs transplanted, IGF-I-treated samples. However, we also saw no real difference in MSC and MEF-transplanted mice with PBS-containing pumps. Previously, we have observed the beneficial effects of MSCs transplant alone as determined by increases in new bone and stronger calluses measured by BMT (GraneroMolto et al. 2009; Granero-Molto et al. 2011). We investigated the possibility that the pump insertion surgery and subsequent wound may be attracting the intravenously transplanted MSCs and therefore blunting the full effect of MSC-dependent fracture healing. Indeed when we compared our $\mu$-CT results in MSC-transplanted mice with and without pumps, we saw a significant decrease in total volume, new bone, and soft tissue volumes in mice with the pump. We speculate that the wound-healing repair process of the implanted region may have recruited circulating MSCs as application of autologous BM-MSC has been reported to induce homing and improve epithelial/dermal wound healing (Sasaki et al. 2008). This is at the expense of the fracture-healing process and explains why there is no difference in MEFs and MSCs treatment. The extent to which the wound interferes with transplanted MSC fracture healing is not fully appreciated at this point. Future experiments using bioluminescent tracking of transplanted cells, and cell dose and transplant timing studies could all be used to determine the exact degree the wound is having on the lack of an MSCdependent fracture healing response.

The mechanisms through which MSCs exert their regenerative effects still need to be fully elucidated. Interestingly, there are an increasing number of studies that indicate that these effects are independent of MSC engraftment and differentiation. Our own work has demonstrated the ability of systemically injected MSCs to home the fracture site but only a small number of cells actually engraft into newly forming tissue in spite of the clear beneficial effects of this treatment (Granero-Molto et al. 2009). Those studies have led to the seed-and-soil MSC regenerative hypothesis postulating that MSCs can secrete, or be carrier of growth factors, that affect the environment at the injured site and that in-vivo MSCs need specific growth factors to be committed to become tissue-specific differentiated cells in order to repair tissue damage (De Bari et al. 2003; Caplan 2007; da Silva Meirelles et al. 2008; Granero-Molto et al. 2009; Lee et al. 2009; Pittenger 2009; Myers et al. 2010; Granero-Molto et al. 2011). This well-supported hypothesis points toward the idea that to enhance their beneficial effects, MSCs need to undergo some sort of genetic manipulation, or growth factor treatment. The results presented here further support this model as only with the combination of IGF-I and MSC transplant did we see the strongest increase in callus volume due to increased new bone and soft tissue formation that was related to an improvement in mechanical properties. Direct evidence for the role of MSCs in fracture healing is still an open question for the field and is the aim of our future experiments.

Genetic engineering of MSCs for use in bone regeneration is a new avenue for MSC-based therapies, but depends on MSCs being appropriately manipulated to express critical levels of factors regulated temporally to promote healing. Animal studies using transplanted MSCs overexpressing BMPs, osteogenic transcription factor RunX2, and VEGF have all induced varying degrees of bone formation (Myers et al. 2010). Recent work from our laboratory demonstrated that $\beta$-galactosidase-positive MSCs retrovirally designed to express IGF-I were able to localize to the fracture site and improve fracture healing while increasing the number of engrafting cells even above MSCs alone through the acceleration of new mineralization and new bone formation (Granero-Molto et al. 2011). The clinical use of retroviral vectors has been banned by the FDA in April of 2003 because the occurrence of 
fatalities including cancer and acute liver failure in patients who received retrovirally based cell therapies. Systemic rhIGF-I therapy is an FDA-approved treatment for IGF-deficient patients, which results in increased longitudinal growth without significant side effects (Klinger and Laron 1995; Chernausek et al. 2007). Several clinical studies have shown that the clinical use of MSCs is safe and feasible (Giordano et al. 2007). In the present study, we have determined that the systemic delivery (by subcutaneous route) of IGF-I concurrent with BM-derived MSC transplant induced significant increases of total soft and new bone callus volumes with degrees that are similar to the those we previously reported by transplanting MSCs retrovirally expressing IGF-I (Granero-Molto et al. 2011). Furthermore, we found that the combined IGF-I + MSC treatment was more effective than either MSC or IGF-I alone. We propose that based on the $\mu$-CT and ISH results, in IGF-I + MSC samples the endochondral ossification process is accelerated, leading to increased new bone as seen by less Col1O and more Osterix and ColIa1. This does not rule out the independent effects whereby the amount of endochondral ossification is increased with either treatment alone, as seen by increases in soft tissue and new bone, Col10 and Osterix in IGF-I alone samples and our previously published enhancement of healing with MSCs alone, but clearly demonstrates the increased amount and accelerated process of the combined treatments. Therefore, our results open the prospective for a realistic clinical approach for treating patients who suffer from impaired or delayed fracture healing by combining the systemic use of IGF-I and MSCs.

An important but still not fully understood aspect of the function of IGF-I is the role of its source in determining the effect. Most of the IGF-I in bone is believed to come from local sources such as pre-osteoblasts, mature osteoblasts, and when released from the bone matrix (Conover 2000). However, liver is a major source for circulating IGF-I which seems to have a major influence on endochondral mediated skeletal growth. Two separate studies showed that by knocking-down the liver-produced IGF-I, circulating IGF-I levels were reduced leading to decreased long bone length and bone density specifically seen in a decline in cortical bone volume (Lupu et al. 2001; Yakar et al. 2002). More recently, Yakar et al. have extended their findings to show that proteins that complex with IGF-I in circulation, such as IGF binding proteins can have effects on the skeletal phenotype, adding another layer of complexion to the regulation and function of IGF-I on bone formation and endochondral cartilage maturation (Yakar et al. 2009). Our study showed that the systemic administration of IGF-I can induce new bone formation, mostly through endochondral ossification, when combined with transplanted MSCs. This finding supports what Fowlkes et al. reported with systemic administration of rhIGF-I that significantly increased new bone formation in aged mice (Fowlkes et al. 2006). Interestingly we found that when we transplanted MSC retrovirally infected to express IGF-I, healing mostly proceeded through intramembranous ossification. Taken together, our and other findings seem to indicate that circulating IGF-I primarily affects the endochondral process, while local IGF-I has a direct effect on osteoblasts. This suggests that future studies will aim at manipulating MSCs and the IGF system in a tissue-specific manner during the fracture repair.

\section{Conclusion}

In conclusion, our study provides evidence that systemically delivered IGF-I and MSCs can ameliorate the fracture-healing process leading to a functionally improved callus through stabilization and accelerated bridging by new bone. Autologous MSC transplant concurrently with IGF-I administration could be a potential novel therapeutic approach for treating patients with non-unions. 


\section{Supplementary Material}

Refer to Web version on PubMed Central for supplementary material.

\section{Acknowledgments}

The authors would like to thank Dr G. Karsenty for providing probes for Col 1a1 and Osterix and Dr D.G. Mortlock for providing the probe for Collo.

\section{References}

Ai-Aql ZS, Alagl AS, Graves DT, Gerstenfeld LC, Einhorn TA. Molecular mechanisms controlling bone formation during fracture healing and distraction osteogenesis. J Dent Res. 2008; 87:107-118. [PubMed: 18218835]

Axelrad TW, Kakar S, Einhorn TA. New technologies for the enhancement of skeletal repair. Injury. 2007; 38(Suppl 1):S49-S62. [PubMed: 17383486]

Bielby R, Jones E, McGonagle D. The role of mesenchymal stem cells in maintenance and repair of bone. Injury. 2007; 38(Suppl 1):S26-S32. [PubMed: 17383482]

Boonen S, Rosen C, Bouillon R, Sommer A, McKay M, Rosen D, Adams S, Broos P, Lenaerts J, Raus J, Vanderschueren D, Geusens P. Musculoskeletal effects of the recombinant human IGF-I/IGF binding protein-3 complex in osteoporotic patients with proximal femoral fracture: A double-blind, placebo-controlled pilot study. J Clin Endocrinol Metab. 2002; 87:1593-1599. [PubMed: 11932288]

Caplan AI. Adult mesenchymal stem cells for tissue engineering versus regenerative medicine. J Cell Physiol. 2007; 213:341-347. [PubMed: 17620285]

Cheng, Z.; Ho, H.; Song, F.; LI, A.; Santa, Maria C.; Wang, Y.; You, M.; Tu, C.; Bikle, D.; Chang, W. Presented at the The American Society of Bone Mineral Research 2011 Annual Meeting; San Diego, CA. September 16-20 2011;

Chernausek SD, Backeljauw PF, Frane J, Kuntze J, Underwood LE. Long-term treatment with recombinant insulin-like growth factor (IGF)-I in children with severe IGF-I deficiency due to growth hormone insensitivity. J Clin Endocrinol Metab. 2007; 92:902-910. [PubMed: 17192294]

Clemens TL, Chernausek SD. Genetic strategies for elucidating insulin-like growth factor action in bone. Growth Hormone IGF Res Off J Growth Hormone Res Soc Int IGF Res Soc. 2004; 14:195199.

Colnot C. Skeletal cell fate decisions within periosteum and bone marrow during bone regeneration. J Bone Miner Res Off J Am Soc Bone Miner Res. 2009; 24:274-282.

Conover CA. In vitro studies of insulin-like growth factor I and bone. Growth Hormone IGF Res Off J Growth Hormone Res Soc Int IGF Res Soc. 2000; 10(Suppl B):S107-S110.

da Silva Meirelles L, Caplan AI, Nardi NB. In search of the in vivo identity of mesenchymal stem cells. Stem Cells. 2008; 26:2287-2299. [PubMed: 18566331]

De Bari C, Dell'Accio F, Vandenabeele F, Vermeesch JR, Raymackers JM, Luyten FP. Skeletal muscle repair by adult human mesenchymal stem cells from synovial membrane. J Cell Biol. 2003; 160:909-918. [PubMed: 12629053]

De Bari C, Dell'Accio F, Vanlauwe J, Eyckmans J, Khan IM, Archer CW, Jones EA, McGonagle D, Mitsiadis TA, Pitzalis C, Luyten FP. Mesenchymal multipotency of adult human periosteal cells demonstrated by single-cell lineage analysis. Arthritis Rheumatism. 2006; 54:1209-1221. [PubMed: 16575900]

Deal KK, Cantrell VA, Chandler RL, Saunders TL, Mortlock DP, Southard-Smith EM. Distant regulatory elements in a Sox10-beta GEO BAC transgene are required for expression of Sox 10 in the enteric nervous system and other neural crest-derived tissues. Dev Dyn. 2006; 235:1413-1432. [PubMed: 16586440]

Di Monaco M, Vallero F, Di Monaco R, Tappero R, Cavanna A. Serum levels of insulin-like growth factor-I are positively associated with functional outcome after hip fracture in elderly women. Am J Phys Med Rehabil. 2009; 88:119-125. [PubMed: 18971769] 
Dominici M, Le Blanc K, Mueller I, Slaper-Cortenbach I, Marini F, Krause D, Deans R, Keating A, Prockop D, Horwitz E. Minimal criteria for defining multipotent mesenchymal stromal cells. International Society for Cellular Therapy position statement. Cytotherapy. 2006; 8:315-317. [PubMed: 16923606]

Einhorn TA. Enhancement of fracture-healing. J Bone Joint Surg Am. 1995; 77:940-956. [PubMed: 7782368]

Fowlkes JL, Thrailkill KM, Liu L, Wahl EC, Bunn RC, Cockrell GE, Perrien DS, Aronson J, Lumpkin CK Jr. Effects of systemic and local administration of recombinant human IGF-I (rhIGF-I) on de novo bone formation in an aged mouse model. J Bone Miner Res Off J Am Soc Bone Miner Res. 2006; 21:1359-1366.

Gerstenfeld LC, Cullinane DM, Barnes GL, Graves DT, Einhorn TA. Fracture healing as a post-natal developmental process: Molecular, spatial, and temporal aspects of its regulation. J Cell Biochem. 2003; 88:873-884. [PubMed: 12616527]

Gerstenfeld LC, Wronski TJ, Hollinger JO, Einhorn TA. Application of histomorphometric methods to the study of bone repair. J Bone Miner Res Off J Am Soc Bone Miner Res. 2005; 20:1715-1722.

Giordano A, Galderisi U, Marino IR. From the laboratory bench to the patient's bedside: An update on clinical trials with mesenchymal stem cells. J Cell Physiol. 2007; 211:27-35. [PubMed: 17226788]

Granero-Molto F, Myers TJ, Weis JA, Longobardi L, Li T, Yan Y, Case N, Rubin J, Spagnoli A. Mesenchymal stem cells expressing insulin-like growth factor-I (MSC(IGF)) promote fracture healing and restore new bone formation in Irs1 knockout mice: Analyses of MSC(IGF) autocrine and paracrine regenerative effects. Stem Cells. 2011; 29:1537-1548. [PubMed: 21786367]

Granero-Molto F, Weis JA, Longobardi L, Spagnoli A. Role of mesenchymal stem cells in regenerative medicine: Application to bone and cartilage repair. Expert Opin Biol Ther. 2008; 8:255-268. [PubMed: 18294098]

Granero-Molto F, Weis JA, Miga MI, Landis B, Myers TJ, O’Rear L, Longobardi L, Jansen ED, Mortlock DP, Spagnoli A. Regenerative effects of transplanted mesenchymal stem cells in fracture healing. Stem Cells. 2009; 27:1887-1898. [PubMed: 19544445]

Guler HP, Zapf J, Froesch R. Short-term metabolic effects of recombinant human insulin-like growth factor I in healthy adults. N Engl J Med. 1987; 317:137-140. [PubMed: 3299085]

Hacein-Bey-Abina S, Hauer J, Lim A, Picard C, Wang GP, Berry CC, Martinache C, Rieux-Laucat F, Latour S, Belohradsky BH, Leiva L, Sorensen R, Debre M, Casanova JL, Blanche S, Durandy A, Bushman FD, Fischer A, Cavazzana-Calvo M. Efficacy of gene therapy for X-linked severe combined immunodeficiency. N Engl J Med. 2010; 363:355-364. [PubMed: 20660403]

Hernigou P, Poignard A, Beaujean F, Rouard H. Percutaneous autologous bone-marrow grafting for nonunions. Influence of the number and concentration of progenitor cells. J Bone Joint Surg Am. 2005; 87:1430-1437. [PubMed: 15995108]

Kanakaris NK, Paliobeis C, Nlanidakis N, Giannoudis PV. Biological enhancement of tibial diaphyseal aseptic non-unions: The efficacy of autologous bone grafting, BMPs and reaming byproducts. Injury. 2007; 38(Suppl 2):S65-S75. [PubMed: 17920420]

Kerr D, Tamborlane WV, Rife F, Sherwin RS. Effect of insulin-like growth factor-1 on the responses to and recognition of hypoglycemia in humans. A comparison with insulin. J Clin Invest. 1993; 91:141-147. [PubMed: 8423214]

Klinger B, Laron Z. Three year IGF-I treatment of children with Laron syndrome. J Pediatric Endocrinol Metab JPEM. 1995; 8:149-158.

Langlois JA, Rosen CJ, Visser M, Hannan MT, Harris T, Wilson PW, Kiel DP. Association between insulin-like growth factor I and bone mineral density in older women and men: The Framingham heart study. J Clin Endocrinol Metab. 1998; 83:4257-4262. [PubMed: 9851760]

Lee RH, Pulin AA, Seo MJ, Kota DJ, Ylostalo J, Larson BL, Semprun-Prieto L, Delafontaine P, Prockop DJ. Intravenous hMSCs improve myocardial infarction in mice because cells embolized in lung are activated to secrete the anti-inflammatory protein TSG-6. Cell Stem Cell. 2009; 5:5463. [PubMed: 19570514]

Liu JP, Baker J, Perkins AS, Robertson EJ, Efstratiadis A. Mice carrying null mutations of the genes encoding insulin-like growth factor I (Igf-1) and type 1 IGF receptor (Igf1r). Cell. 1993; 75:59-72. [PubMed: 8402901] 
Lupu F, Terwilliger JD, Lee K, Segre GV, Efstratiadis A. Roles of growth hormone and insulin-like growth factor 1 in mouse postnatal growth. Dev Biol. 2001; 229:141-162. [PubMed: 11133160]

Mahendra A, Maclean AD. Available biological treatments for complex non-unions. Injury. 2007; 38(Suppl 4):S7-S12. [PubMed: 18224732]

Marsh D. Concepts of fracture union, delayed union, and nonunion. Clin Orthopaedics Relat Res. 1998; 355s:S22-S30.

Myers TJ, Granero-Molto F, Longobardi L, Li T, Yan Y, Spagnoli A. Mesenchymal stem cells at the intersection of cell and gene therapy. Expert Opin Biol Ther. 2010; 10:1663-1679. [PubMed: 21058931]

Nakasaki M, Yoshioka K, Miyamoto Y, Sasaki T, Yoshikawa H, Itoh K. IGF-I secreted by osteoblasts acts as a potent chemotactic factor for osteoblasts. Bone. 2008; 43:869-879. [PubMed: 18718566]

Nauta AJ, Fibbe WE. Immunomodulatory properties of mesenchymal stromal cells. Blood. 2007; 110:3499-3506. [PubMed: 17664353]

Pittenger M. Sleuthing the source of regeneration by MSCs. Cell Stem Cell. 2009; 5:8-10. [PubMed: 19570508]

Powell-Braxton L, Hollingshead P, Warburton C, Dowd M, Pitts-Meek S, Dalton D, Gillett N, Stewart TA. IGF-I is required for normal embryonic growth in mice. Genes Dev. 1993; 7:2609-2617. [PubMed: 8276243]

Praemer, A.; Furner, S.; Rice, DP. Musculoskeletal conditions in the United States. 2. Park Ridge, IL: The American Academy of Orthopaedic Surgeons; 1999.

Prockop DJ. Marrow stromal cells as stem cells for nonhematopoietic tissues. Science. 1997; 276:7174. [PubMed: 9082988]

Prockop DJ. Repair of tissues by adult stem/progenitor cells (MSCs): Controversies, myths, and changing paradigms. Mol Ther. 2009; 17:939-946. [PubMed: 19337235]

Prockop DJ, Olson SD. Clinical trials with adult stem/ progenitor cells for tissue repair: Let's not overlook some essential precautions. Blood. 2007; 109:3147-3151. [PubMed: 17170129]

Raschke M, Wildemann B, Inden P, Bail H, Flyvbjerg A, Hoffmann J, Haas NP, Schmidmaier G. Insulin-like growth factor-1 and transforming growth factor-beta1 accelerates osteotomy healing using polylactide-coated implants as a delivery system: A biomechanical and histological study in minipigs. Bone. 2002; 30:144-151. [PubMed: 11792577]

Reynolds DG, Hock C, Shaikh S, Jacobson J, Zhang X, Rubery PT, Beck CA, O'Keefe RJ, Lerner AL, Schwarz EM, Awad HA. Micro-computed tomography prediction of biomechanical strength in murine structural bone grafts. J Miomech. 2007; 40:3178-3186.

Rosen CJ, Dimai HP, Vereault D, Donahue LR, Beamer WG, Farley J, Linkhart S, Linkhart T, Mohan S, Baylink J. Circulating and skeletal insulin-like growth factor-I (IGF-I) concentrations in two inbred strains of mice with different bone mineral densities. Bone. 1997; 21:217-223. [PubMed: 9276086]

Sasaki M, Abe R, Fujita Y, Ando S, Inokuma D, Shimizu H. Mesenchymal stem cells are recruited into wounded skin and contribute to wound repair by transdifferentiation into multiple skin cell type. J Immunol. 2008; 180:2581-2587. [PubMed: 18250469]

Schmidmaier G, Wildemann B, Heeger J, Gabelein T, Flyvbjerg A, Bail HJ, Raschke M. Improvement of fracture healing by systemic administration of growth hormone and local application of insulinlike growth factor-1 and transforming growth factor-beta1. Bone. 2002; 31:165-172. [PubMed: 12110430]

Spagnoli A, Longobardi L, O'Rear L. Cartilage disorders: Potential therapeutic use of mesenchymal stem cells. Endocrine Dev. 2005; 9:17-30.

Trippel SB. Potential role of insulinlike growth factors in fracture healing. Clin Orthopaedics Relat Res. 1998; 355s:S301-S313.

Uccelli A, Moretta L, Pistoia V. Mesenchymal stem cells in health and disease. Nature reviews Immunology. 2008; 8:726-736.

Wang Y, Nishida S, Sakata T, Elalieh HZ, Chang W, Halloran BP, Doty SB, Bikle DD. Insulin-like growth factor-I is essential for embryonic bone development. Endocrinology. 2006; 147:47534761. [PubMed: 16857753] 
Weis JA, Miga MI, Granero-Molto F, Spagnoli A. A finite element inverse analysis to assess functional improvement during the fracture healing process. J Biomech. 2010; 43:557-562. [PubMed: 19875119]

Yakar S, Canalis E, Sun H, Mejia W, Kawashima Y, Nasser P, Courtland HW, Williams V, Bouxsein M, Rosen C, Jepsen KJ. Serum IGF-1 determines skeletal strength by regulating subperiosteal expansion and trait interactions. J Bone Miner Res Off J Am Soc Bone Miner Res. 2009; 24:14811492.

Yakar S, Rosen CJ, Beamer WG, Ackert-Bicknell CL, Wu Y, Liu JL, Ooi GT, Setser J, Frystyk J, Boisclair YR, LeRoith D. Circulating levels of IGF-1 directly regulate bone growth and density. J Clin Invest. 2002; 110:771-781. [PubMed: 12235108]

Zhao G, Monier-Faugere MC, Langub MC, Geng Z, Nakayama T, Pike JW, Chernausek SD, Rosen CJ, Donahue LR, Malluche HH, Fagin JA, Clemens TL. Targeted overexpression of insulin-like growth factor I to osteoblasts of transgenic mice: Increased trabecular bone volume without increased osteoblast proliferation. Endocrinology. 2000; 141:2674-2682. [PubMed: 10875273] 
A

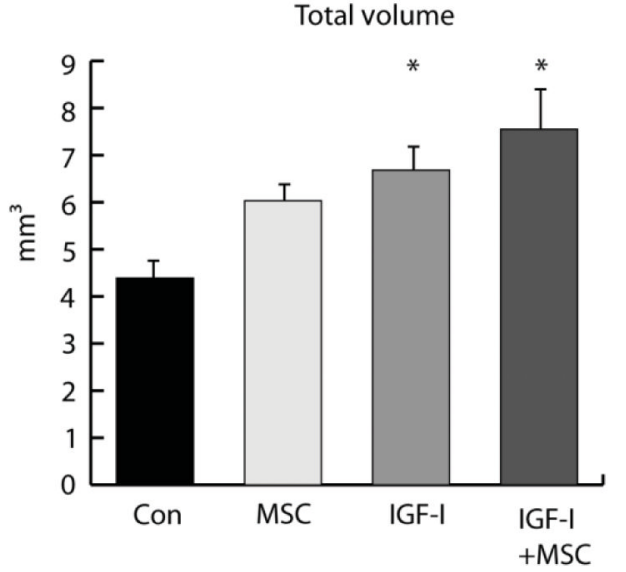

B

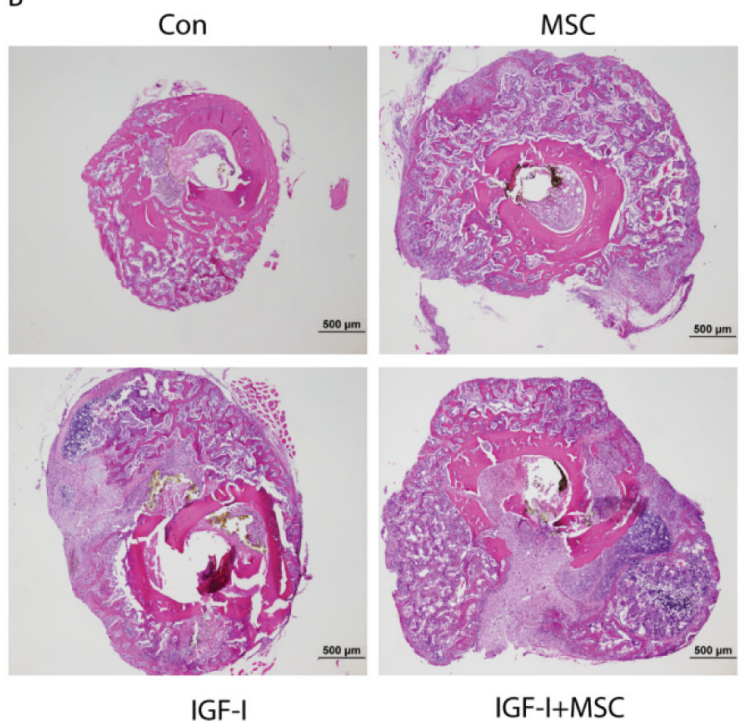

Figure 1.

Systemic IGF-I combined with MSC transplant increases the total callus volume. (A) $\mu-C T$ analyses were performed 14 days after tibial fracture in mice that were implanted with osmotic pumps containing PBS and were left untransplanted (control, Con, $n=7$ ), or received $1 \times 10^{6} \mathrm{MSCs}$ intravenous transplant (MSC, $\left.n=5\right)$ and mice that were implanted with osmotic pump delivering IGF-I (50 $\mu \mathrm{g} / \mathrm{kg} /$ day) and either left untransplanted (IGF-I, $n$ =9) or received MSC transplant (IGF-I + MSC, $n=6$ ). Volumetric analysis for the callus total volume was performed as described in the Methods section. Statistical analyses were performed using one-way ANOVA $(p<0.0035)$ followed by Bonferroni's Multiple Comparison post-hoc test; ${ }^{*} p<0.05$ compared to control. (B) H\&E staining of 14-day postfracture transversal sections of paraffin-embedded samples from each group representative of the fracture center. The entire callus was sectioned (6- $\mu \mathrm{m}$-thick sections), the fracture center was identified by the largest diameter of callus size in which the fracture line was clearly demarked by H\&E staining. Sections were obtained from one (ConMSC) or two samples (Con, IGF-I, and IGF-I + MSC). Magnifications presented are 4X. 

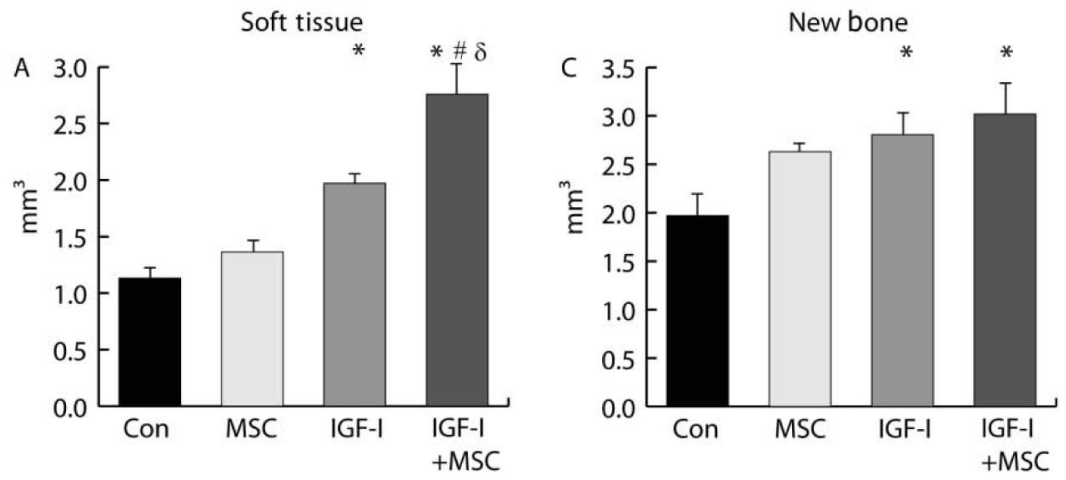

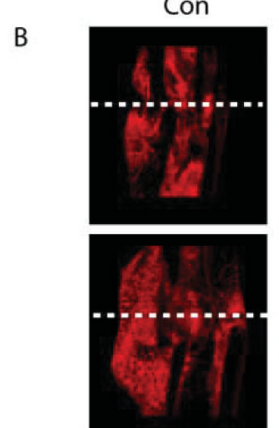

IGF-I
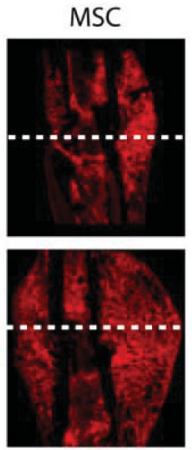

IGF-I

+ MSC

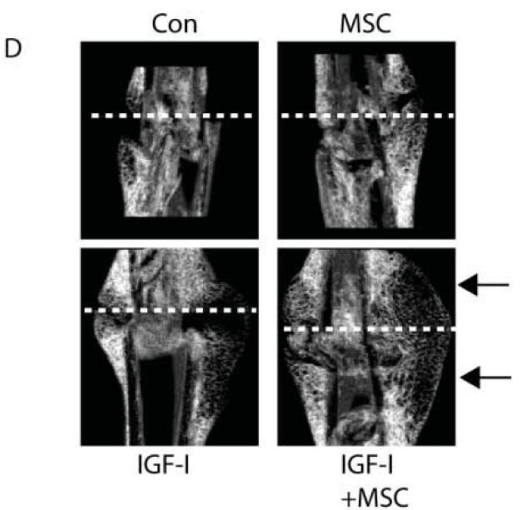

Figure 2.

IGF-I + MSC increases the soft tissue and new bone volumes. $\mu-C T$ analyses were performed 14 days after tibial fracture in mice that were implanted with osmotic pumps containing PBS and were left untransplanted (control, Con, $n=7$ ), or received $1 \times 10^{6}$ MSCs intravenous transplant (MSC, $n=5$ ) and mice that were implanted with osmotic pump delivering IGF-I ( $50 \mu \mathrm{g} / \mathrm{kg} /$ day) and either left untransplanted (IGF-I, $n=9$ ) or received MSCs transplant (IGF-I + MSC, $n=6$ ). Soft tissue volume (A) or new bone volume $(\mathrm{C})$ was quantified using our previously reported thresholding study (Granero-Molto et al. 2009). Statistical analyses were performed using one-way ANOVA $(p<0.0001$ for soft tissue; $p<0.042$ for new bone) followed by Bonferroni's Multiple Comparison post-hoc test $* p<0.05$ versus control; ${ }^{\#} p<0.05$ versus MSC; ${ }^{\delta} p<0.05$ versus IGF-I. Lower panels are representative $\mu$-CT reconstructions of coronal sections $(360 \mu \mathrm{m}$ in width) surrounding the center of the fracture callus (dashed lines) of either soft tissue (B) or new bone (D). Arrowheads indicate the formation of new bone bridging the fracture line and callus edges. 

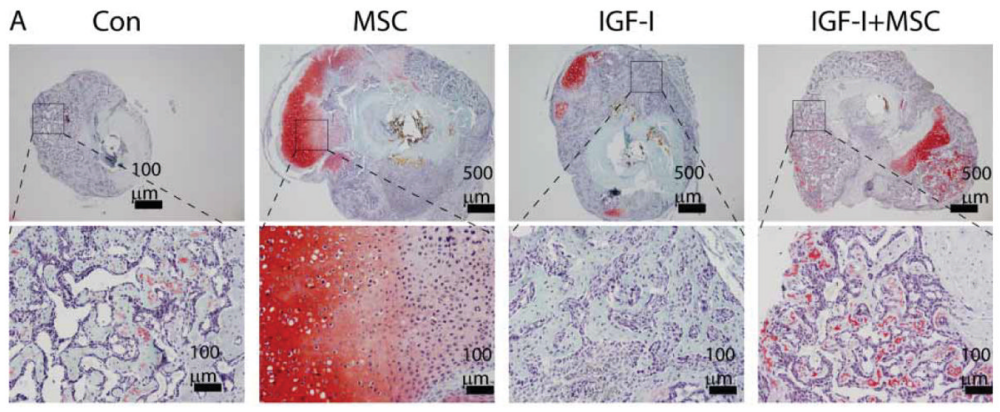

B

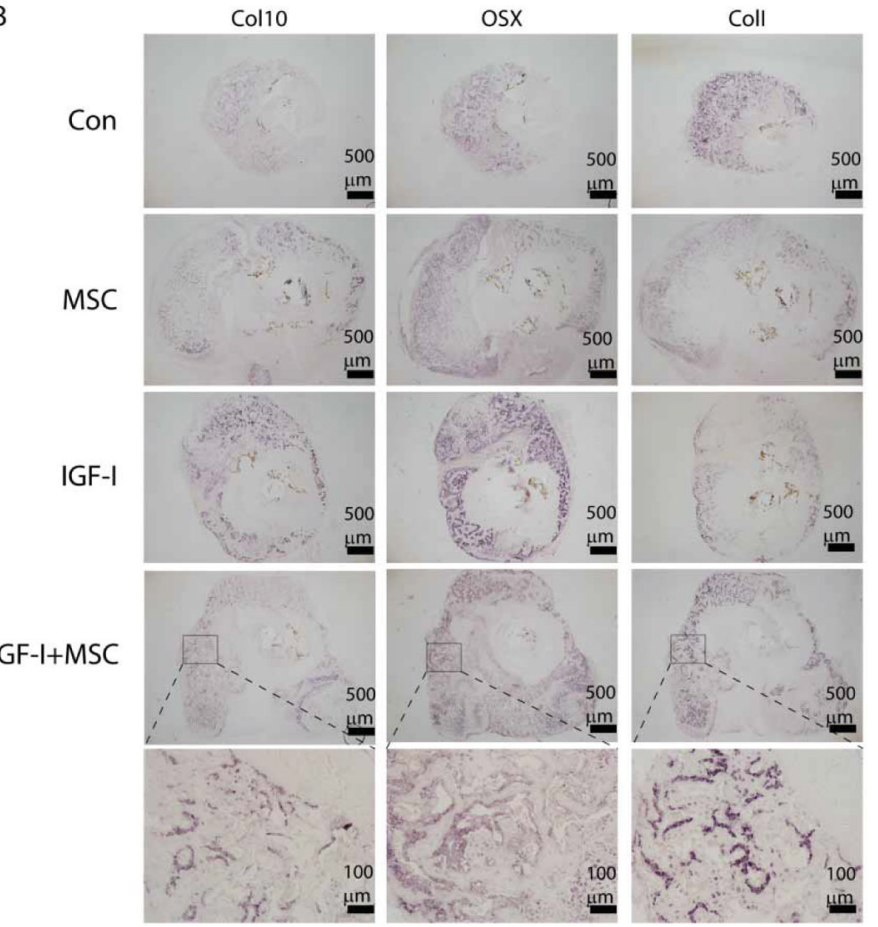

Figure 3.

IGF-I + MSC induces endochondral ossification. Calluses were obtained 14 days after tibial fracture from mice that were implanted with osmotic pumps containing PBS which were left untransplanted (Con), or received $1 \times 10^{6}$ MSCs intravenous transplant (MSC) and mice that were implanted with osmotic pump delivering IGF-I and either left untransplanted (IGF-I) or received MSC transplant (IGF-I + MSC). (A) The fracture center sections were subjected to Safranin O/Fast Green staining (SafO/FG). Safranin O/Fast Green stain, respectively, for the presence of cartilage (red) and bone (green). (B) In-situ hybridization for either Collagen $X(\mathrm{Col10})$, Osterix (OSX), or Collagen Ia1 (Col1). Analyses were done for at least three sections for each probe or staining. Sections were obtained from one (Con MSC) or two samples (Con, IGF-I, and IGF-I + MSC). Representative studies are depicted.

Magnifications presented are $4 \times$ or $20 \times$. 

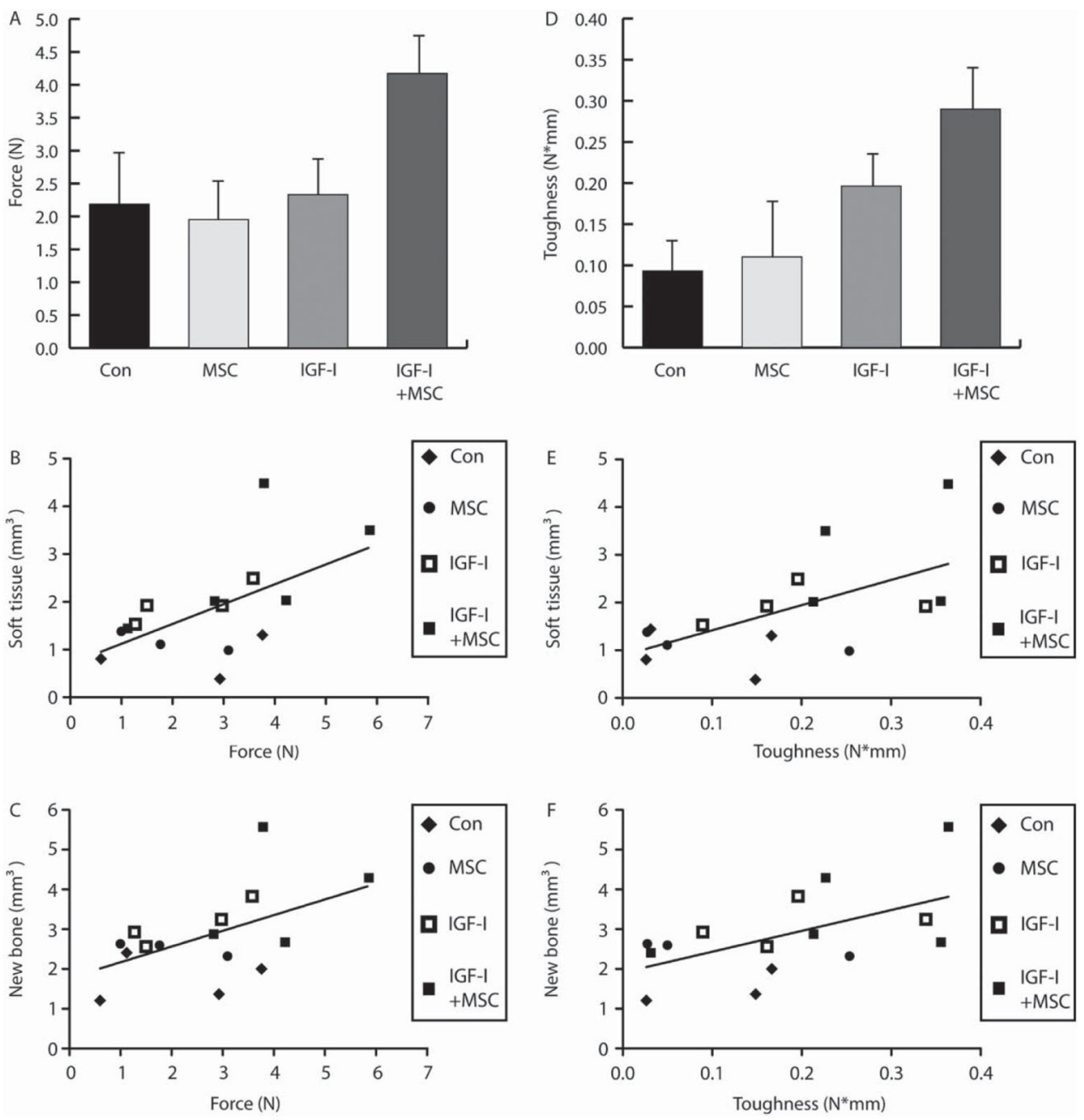

Figure 4.

Effects of systemic IGF-I and MSC transplant on the biomechanical properties of the callus. Fourteen days post-fracture tibias were obtained from mice that were implanted with osmotic pumps containing PBS and were left untransplanted (Con, $n=4)$, or received $1 \times$ $10^{6}$ MSCs intravenous transplant (MSC, $n=3$ ) and mice that were implanted with osmotic pump delivering IGF-I and either left untransplanted (IGF-I, $n=4$ ) or received MSC transplant (IGF-I + MSC, $n=4$ ). Following dissection, calluses were subjected to distraction-to-failure BMT to determine the callus material properties. The bar graphs represent, respectively, the ultimate force (A) and toughness (D), while the middle and lower graphs represent the linear regression analyses between the callus soft tissue and the ultimate force (B, $\left.p<0.024 ; r^{2}=0.33\right)$ and toughness $\left(\mathrm{E}, p<0.02 ; r^{2}=0.35\right)$ or between the new bone and the ultimate force $\left(\mathrm{C}, p<0.045 ; r^{2}=0.27\right)$ and toughness $\left(\mathrm{F}, p<0.03 ; r^{2}\right.$ $=0.31$. 